\title{
What is Special about De Se Attitudes?
}

\author{
Stephan Torre and Clas Weber \\ University of Aberdeen \& University of Western Australia
}

\section{Introduction}

De se attitudes seem to play a special role in action and cognition. This raises a challenge to the traditional way in which mental attitudes have been understood. In this chapter, we review the case for thinking that de se attitudes require special theoretical treatment and discuss various ways in which the traditional theory can be modified to accommodate de se attitudes.

In $\S 2$, we give a tentative characterization of indexical and de se attitudes, outline the traditional theory, and then present the main theoretical accounts of de se attitudes. In $\S 3$, we discuss the question of whether de se attitudes play a special role in cognition and analyze their relation to Frege's puzzle. In $\S 4$, we discuss the question of whether de se attitudes play a special role in explaining action. In $\S 5$, we consider the claim that de se judgments are immune to error through misidentification.

\section{Indexical Attitudes, De Se Attitudes, and the Traditional Theory}

There is an intuitive contrast between beliefs which represent the world from a god's eye perspective and beliefs that concern our place within the world, i.e. beliefs about who we are, what we are like, and where we are spatiotemporally located. For instance, you may believe that quarks exist, that metals conduct electricity, or that $2+2=4$. These beliefs do not concern your place in the larger order of things. On the other hand, you may think that you are Napoleon, that today is Monday, or that you are currently in Helsinki. Indexical beliefs are beliefs of the latter type. The distinction also holds for other types of attitudes, e.g. you may fear that metals conduct electricity, or hope that you are currently in Helsinki.

It is difficult to give a more explicit definition of indexical attitudes which is also theoryneutral. Indexical attitudes are often characterized in relation to linguistic indexicality, as attitudes whose expression or ascription involves indexical sentences. Linguistic indexicality (in a broad sense) can in turn be defined in a straightforward way: an expression $e$ is indexical (or context-sensitive) iff its extension depends on the context, i.e. iff there are contexts $c, c^{*}$ such that $\llbracket e \rrbracket^{c} \neq \llbracket e \rrbracket^{c^{*}}$ (Kaplan, 1989; Zimmermann, 1991). ${ }^{1}$

This characterization gets many cases right, but it is not entirely adequate. Sometimes, indexical attitudes are expressed in a non-indexical manner. For instance, LeBron James might express his indexical belief I do what is best for me with the sentence: "LeBron James does what is best for LeBron James.". Similarly, not all attitudes ascribed by an indexical sentence

\footnotetext{
${ }^{1}$ If one does not want to count contingency as a form of indexicality, one should take the quantifier to range over contexts within the same world.
} 
are indexical. Pointing to LeBron James, I might report Aren's non-indexical belief LeBron James is the greatest player of all time with the indexical sentence: "Aren believes that he is the greatest player of all time".

One might try to give a definition of mental indexicality that mirrors the above definition of linguistic indexicality: a belief $b$ is indexical iff its truth-value depends on the context, i.e. iff there are contexts $c, c^{*}$ such that $\llbracket b \rrbracket^{c} \neq \llbracket b \rrbracket^{c^{*}}$. But this approach also faces difficulties. The identification of linguistic expressions across contexts is relatively uncontroversial, but this is not the case for attitudes. Many think that judging on both Monday and Tuesday Today is Monday involves different beliefs, rather than the same belief in different contexts.

The best option may be to give an ostensive definition (Ninan, 2016), i.e. point to clear examples and define indexical attitudes as attitudes of the same kind. As sample cases we can use famous examples from the literature, such as Perry's messy shopper, or we might rely on the phenomenology of inner speech and focus on cases where we explicitly make internal indexical judgments, such as Oh dear, I am making a mess right now. Below, we will also consider the main accounts of indexical attitudes and corresponding theory-internal definitions.

Assume that we have a satisfactory understanding of indexical attitudes. What, then, are de se attitudes? There are two options. According to the dominant view, de se attitudes are a special subset of the set of indexical attitudes, where we represent ourselves in a special, first-personal manner. Relatedly, de nunc attitudes are attitudes in which we represent the present time as now. On a different view, there is no interesting contrast between de se/de nunc attitudes and other indexical attitudes. ${ }^{2}$ The motivation for this understanding of de se attitudes is that indexical attitudes seem in general a priori equivalent to complex I-now attitudes. For instance, attitudes about here are equivalent to attitudes about the place where I am now; attitudes about that thing are equivalent to attitudes about the thing I am now pointing to, and so on. ${ }^{3}$ Further, indexical attitudes also exhibit many of the features that make de se attitudes theoretically interesting. We will in the following assume a conception of de se attitudes according to which de se and de nunc attitudes are a proper subset of indexical attitudes.

We can distinguish the main accounts of de se attitudes in terms of how they diverge from what we will call the Traditional Theory of Attitudes. This theory has the following commitments:

\section{The Traditional Theory of Attitudes}

Binary Relationism: Attitudes are binary relations between subjects and contents.

Absolutism: Attitude contents vary in truth-value at most between different possible worlds.

\footnotetext{
2 In the following, we will mostly just focus on de se attitudes.

3 See (Perry, 1979) for this suggestion; see (Chalmers, 2011) for the claim that this reduction fails and that we need primitive experiential demonstratives (or at least an orientation) to deal with 'two tubes cases' (Austin, 1990).
} 
Shareability: It is possible for different subjects to be related to the same content.

The Traditional Theory treats attitudes as binary relations between subjects and absolute and non-private contents. Contents are abstract entities postulated for two main explanatory tasks: first, they should account for the role of attitudes in rationalizing and explaining behavior; second, they should account for the cognitive significance of attitudes, i.e. their representational content and rational connections to other attitudes. Accounts of contents that are absolute and shareable have been given in terms of sets of possible worlds or structured Russellian propositions.

In the late 1970s, John Perry $(1977,1979)$ and David Lewis $(1979)$ convinced many that the Traditional Theory is inadequate because it fails to accommodate indexical attitudes. Several rival accounts of attitudes have been proposed which abandon different commitments of the theory. While differing superficially, on a deeper level they have more in common than is ordinarily acknowledged. Below we outline different ways in which the Traditional Theory can be modified to accommodate indexical attitudes.

Relativism Relativists, such as Lewis (1979), abandon Absolutism. They take contents to be not true or false absolutely, but only relative to subjects or times. Relativistic contents can be identified with sets of centered possible worlds (Lewis, 1979). A centered world is a pair of a possible worlds and a center. Centers can in turn be modelled as spatio-temporal locations, or as pairs of a spatio-temporal location and an individual. ${ }^{4}$ In principle, Relativists could treat indexical attitudes as relations between subjects and relativistic contents, and non-indexical attitudes as relations to absolute contents. However, that would lead to a doubling of attitudinal relations: for each attitude we would need two different relations, one linking to relativistic contents, the other to absolute ones. Lewis's simpler proposal is to treat indexical and non-indexical attitudes alike as binary relations between subjects and relativistic contents. ${ }^{5}$ Even though all attitudes are relations to relativistic contents, i.e. sets of centered worlds, some sets of centered worlds are interesting, others are boring (Egan, 2007). Boring contents map all centers within a possible world to the same truth value. Interesting contents map some centers indexed to the same world to different truth values. Indexical attitudes can then be defined as attitudes with interesting contents; non-indexical attitudes, on the other hand, have boring contents. Relativists may try to define de se attitudes as indexical attitudes that directly impose a condition on the center-individual. For instance, the content of the de se belief I am happy is the set of centered worlds, such that the center-individual is happy (at the time of the center). But it is unclear whether this can be made more precise

\footnotetext{
${ }^{4}$ Chalmers (2011), in relation to the concern from fn3, maintains that centers need to include further parameters.

${ }^{5}$ Lewis (1979) explicitly mentions the relation corresponding to belief, i.e. that of self-ascribing a relativistic content. Relations corresponding to other types of attitudes can be understood analogously. For instance, the relation of hoping is that relation which holds between a subject and the set of centered worlds, such that the center-individual is the way the subject hopes to be.
} 
and the approach is most naturally combined with the view that there is no deep distinction between de se/de nunc attitudes and indexical attitudes more generally.

Relativism can salvage many of the advantages of the Traditional Theory. Maintaining Binary Relationism and Shareabililty enables the comparison of attitudes across people and times, as well as the explanation of behavioral and cognitive patterns in terms of content. Relativism is the dominant position within the quantitative approach to attitudes, as centered propositions can easily be incorporated into the Bayesian set-theoretic framework (Chalmers, 2011; Titelbaum, 2016). A seeming downside is that relativistic accounts of belief-updating (Meacham, 2010; Schwarz, 2012) and communication (Gibbard, 2012; Weber, 2013) are more complicated than standard approaches. But the standard approaches are founded on the simplistic Traditional Theory; compared to other non-traditional approaches, Relativism does not fare worse.

Guises Absolutism The main alternative to Relativism is Guises Absolutism. Officially, Guises Absolutists abandon Binary Relationism and leave the traditional conception of content untouched. Attitudes are treated as ternary relations between subjects, traditional propositions, and propositional guises. Guises Absolutism was proposed by Perry (1979) and is endorsed by Neo-Russellians (Salmon, 1986; Soames, 1987; Braun, 2002). ${ }^{6}$ The mental-file approach of Recanati (2012b, 2016) also belongs to this category.

On this view, indexical attitudes are relations between subjects, contents/propositions, and indexical guises. De se attitudes are attitudes that involve a special first-personal guise. For instance, Claudia's de se belief I like fairies is analyzed as a relation between i.) Claudia ii.) the content that Claudia likes fairies and iii.) a first-personal guise.

Two questions arise with respect to guises: First, what exactly are they? Second, how do guises manage to fulfil their explanatory roles? For instance, Perry (1979) treats guises as entities similar to Kaplanian characters. This aims to provide an answer to both questions. However, others treat guises as primitive entities (e.g. Frege, 1892) leaving both questions unanswered.

Guises Absolutists acknowledge that traditional contents cannot explain attitudes' behavioral and cognitive role all by themselves-hence the need to supplement contents with guises. This suggests a different way of looking at things (Weber, 2016; Ninan, 2016; Torre and Weber, forthcoming). Above, we have introduced the technical term content by its two central explanatory roles. Since the entities that play these roles are not traditional contents alone, but rather traditional contents in combination with guises, it seems more appropriate for Guises Absolutists to identify contents with pairs of the form: <guise; traditional content>. According to this interpretation, the approach can be seen as abandoning Shareability rather than Binary Relationism. Claudia's de se belief is a binary relation between her and the

\footnotetext{
${ }^{6}$ Perry uses the term 'belief state' for what we are here calling 'guises'.
} 
ordered content pair <"I like fairies"; that Claudia likes fairies>. ${ }^{7}$ Only Claudia can be related to this pair, since only she can have beliefs about Claudia under the first-personal-guise.

\section{Russellian Absolutism}

It is possible to give an Absolutist account of indexical attitudes that avoids guises. Call this view Russellian Absolutism. Russellian Absolutism maintains Binary Relationism and explicitly abandons Shareability. The view encompasses four key claims (Weber, 2016). First, de se and de nunc attitudes are relations to singular contents concerning the subject S or the present time t. Second, non-indexical attitudes are relations to qualitative contents. Third, only $S$ can entertain singular contents about $S$, and only at $t$ can we grasp singular contents about $t$. Fourth, every subject $S$ at time $t$ knows a priori and with certainty that they are $\mathrm{S}$ and that the present time is $\mathrm{t}^{8}$

Here, $\mathrm{S}$ and $\mathrm{t}$ can play the role that centers play in Relativism. For instance, Relativists model S's spatial indexical ignorance as involving several differently located centers within a possible world; Russellian Absolutists instead employ several qualitatively identical worlds that differ merely in S's location.

Pluralism Pluralists associate attitudes with several contents, which play different theoretical roles. Its main proponents are Perry (2001) and Chalmers (2002; 2011). According to Chalmers (2011), beliefs can be associated with (at least) two contents: a primary intension and a secondary intension. Primary intensions resemble relativistic contents; secondary intensions resemble traditional absolute contents. We can also associate beliefs with enriched intensions which are complexes of primary and secondary intensions. Enriched intensions can do the combined explanatory work of primary and secondary intensions. Pluralism thus understood sacrifices Shareability-only Claudia can be related to the enriched intension $<$ that I like fairies; that Claudia likes fairies >. ${ }^{9}$ Pluralists can define de se attitudes in the same way as Relativists, focusing on the first element of content, and add further that the second element is a singular content about the subject.

The different accounts of de se belief agree in important respects. All acknowledge that contents, i.e. the entities which play the relevant theoretical roles, cannot both be absolute and shareable at the same time. All accept that reference is often mediated. All maintain that certain referential relations, e.g. to the subject or the present time, have to be accepted as fundamental (either explicitly as Russellian Absolutists, or implicitly as Relativists). And all assign de se attitudes a special theoretical status in that they require a modification of the Traditional Theory. There are two main lines of argument for the last claim, corresponding to the two above-mentioned theoretical roles. The first relies on the role of de se attitudes in

\footnotetext{
${ }^{7}$ Here, we have indicated propositional guises by corresponding English sentences, and traditional contents by a that-clause. It is now doubtful whether contents thus construed still count as absolute (Weber, 2016).

${ }^{8}$ As the label indicates, an account along these lines has been proposed by Russell (1912); and a similar approach has been advocated by Stalnaker (1999). However, neither Russell nor Stalnaker endorse all four claims.

${ }^{9}$ The indexical that-clause represents the belief's relativistic primary intension, the non-indexical that-clause represent its absolute secondary intension.
} 
cognition and rational inference; the second relies on their role in action. We will consider them in turn in the following sections.

\section{The Cognitive Role of De Se beliefs}

\subsection{Three Arguments from De Se Attitudes Against the Traditional Theory}

De se beliefs seem to play a special role in cognition. They seem to convey a distinctive, indexical type of information, irreducible to the information encoded in non-indexical, objective beliefs. Perhaps the most famous case for this claim is Lewis's story of the two gods (Lewis, 1979); Lewis uses the term "proposition" to refer to traditional (i.e. absolute and shareable) contents.

[The two gods] inhabit a certain possible world, and they know exactly which world it is. Therefore they know every proposition that is true at their world. Insofar as knowledge is a propositional attitude, they are omniscient. Still I can imagine them to suffer ignorance [...]. Neither one knows whether he lives on the tallest mountain or on the coldest mountain [...].

Surely, their predicament is possible. [...] But if it possible to lack knowledge and not lack any propositional knowledge, then the lacked knowledge must not be propositional. (Lewis, 1979, pp. 520-521)

The scenario Lewis describes seems conceivable and hence possible. But its possibility is incompatible with the Traditional Theory of Attitudes. Therefore, the theory is inadequate. We can turn Lewis's story into an explicit argument against the Traditional Theory:

\section{Lewis's Indexical Knowledge Argument}

1. Conceivability: It is conceivable to be omniscient with respect to every proposition true at the world while having de se ignorance (i.e. ignorance about who or where one is).

2. Conceivability-Possibility: If it is conceivable to be omniscient with respect to every proposition true at the word while having de se ignorance, then this is possible.

3. Possibility: Hence, it is possible to be omniscient with respect to every proposition true at the world while having de se ignorance

4. Traditional Theory and Omniscience: The Traditional Theory of Attitudes entails that it is not possible to be omniscient with respect to every proposition true at the world while having de se ignorance.

5. Conclusion: The Traditional Theory of Attitudes is flawed.

The argument resembles Jackson's knowledge argument (Jackson, 1982). ${ }^{10}$ Both rely on the idea that complete knowledge in one domain (physical facts vs. objective facts) is compatible

10 This similarity has been noted by Stalnaker (2008) and Kwon (2017). 
with ignorance in another domain (phenomenal facts vs. indexical facts). According to the Traditional Theory, all attitudes, including de se attitudes, are binary relations between subjects and propositions (i.e. traditional contents). So, possessing de se knowledge is to know that the relevant proposition is true. The theory therefore implies that a subject who knows all true propositions also has complete de se knowledge. While some commentators have questioned the coherence of the scenario (Stalnaker, 2008; Kwon, 2010), ${ }^{11}$ the main complaint has been that the argument is question-begging (e.g. Stalnaker, 1981; Cappelen and Dever, 2013). In its present form, the criticism seems apt. The problem is that Lewis formulates his case using the technical term "proposition". This hampers a pre-theoretical assessment of Conceivability and seems to prejudge the question of whether indexical knowledge is propositional knowledge. A way to remedy this issue is to put the argument in more neutral terminology, replacing "knowledge with respect to propositions" with "objective knowledge".

\section{The Indexical Knowledge Argument}

1. Conceivability: It is conceivable to have all objective knowledge while having de se ignorance.

2. Conceivability-Possibility: If it is conceivable to have all objective knowledge while having de se ignorance, then this is possible.

3. Possibility: Hence, it is possible to have all objective knowledge while having de se ignorance.

4. Traditional Theory and Omniscience: The Traditional Theory of Attitudes entails that it is not possible to have all objective knowledge while having de se ignorance.

5. Conclusion: The Traditional Theory of Attitudes is flawed.

To assess this argument, we need an explanation of objective knowledge. The central idea is that objective knowledge is the possession of information which is shareable and standpointindependent, i.e. not bound to a certain context or individual. Thus understood, Conceivability is both pre-theoretically plausible and assuming its truth seems no longer question-begging. We can imagine the gods having a "god's eye view on the world", i.e. an all-encompassing perspective that doesn't privilege any specific viewpoint. We can further imagine that their view of the world is perfect-they know, in this objective, non-perspectival manner, everything that is going on in their world. ${ }^{12}$

In the original formulation, Traditional Theory and Omniscience was true by definition. This is no longer the case for the modified argument. Still, the premise seems compelling. Traditional contents are absolute and shareable, i.e. their truth does not depend on who considers them when and they can be grasped by any subject with the appropriate cognitive

\footnotetext{
${ }^{11}$ Stalnaker (2008) has questioned whether the god's ignorance is compatible with their role as agents. But it is not essential for the argument that the gods are agents. All the argument really requires is that the gods have a spatiotemporal location, e.g. by possessing a physical body.

12 Lewis writes: "[...] perhaps [...] they have an equally perfect view of their world, and hence cannot identify the perspective from which they view it." (Lewis, 1979, p. 521).
} 
resources. There should therefore be no obstacle to acquiring such contents in an objective manner. Hence, someone who knows all contents which are knowable in an objective way should know all knowable contents whatsoever.

A defender of the traditional theory may resist the conclusion by insisting that de se ignorance is failure to know a traditional content and that the scenario is therefore impossible, or by claiming that the notion of objective knowledge is either tendentious or unclear. We can sidestep these concerns by modifying Lewis's case (Weber, 2015, 2016). Assume that the gods have resolved their de se ignorance and are now completely omniscient, both with respect to objective truths and de se truths. According to the traditional theory, they are now belief-related to all and only true contents. (We can further assume that the gods also share all other attitudes towards traditional contents.) But according to the traditional theory, subjects who share all attitudinal relations to traditional contents cannot differ cognitively. Yet, the god's perspectives are not the same: e.g. the god one on the highest mountain believes I am on the highest mountain, while the god on the coldest mountain believes I am on the coldest mountain. These perspectival differences seem to be cognitive: they correspond to differences in representational contents (at least in one sense), differences in rational inferences, and differences in behavioral dispositions. We can summarize this argument as follows:

\section{The Perspectives Argument}

1. Traditional Theory and Cognitive Sameness: The Traditional Theory of Attitudes entails that subjects who stand in the same attitudinal relations to absolute contents are cognitively indistinguishable.

2. Different Perspectives: It is possible for subjects who stand in the same attitudinal relations to absolute contents to differ in de se attitudes.

3. Perspectival Difference-Cognitive Difference: Subjects who differ in de se attitudes differ cognitively.

4. Cognitive Difference: Hence, there are subjects who stand in the same attitudinal relations to absolute contents but differ cognitively.

5. Conclusion: The Traditional Theory of Attitudes is flawed.

The final argument concerning the special cognitive role of de se beliefs we will consider concerns how de se knowledge can be acquired. The Traditional Theory seems to imply that one might in principle acquire de se knowledge in an objective manner. Using a somewhat simplistic metaphor, we may imagine that there is a Book of the World that contains all truths about the world. In principle, one should be able to learn every fact from reading the book. But this seems impossible for de se truths. Consider two subjects, Ani and Aren. Assume they start from a state of absolute ignorance. Then they are handed the Book of the World. Can they learn who they are just from reading the book? It doesn't seem so. Since both have the exact same informational resources and are both starting from a state of absolute ignorance, it would be odd if they arrived at different conclusions. It would seem unjustified for Aren to infer I am Aren and for Ani to infer the different conclusion I am Ani. What could be the 
rational ground for these differences, if all they had to go on is what's written in the book? ${ }^{13}$ These considerations can be summarized in the following argument:

\section{The Learning Argument}

1. Indexical Learning: It is not possible to learn all graspable de se truths merely from learning which absolute contents are true.

2. Impossible Learning: Hence, it is not possible to learn all graspable truths merely from learning which absolute contents are true.

3. Traditional Theory and Learning: The Traditional Theory of Attitudes entails that it is possible to learn all graspable truths merely from learning which absolute contents are true.

4. Conclusion: The Traditional Theory of Attitudes is flawed.

To be compelling, each argument would need further elaboration. Still, together they form a strong negative case: de se attitudes cannot be accounted for in the confines of the Traditional Theory. But they do not tell us which alternative to choose instead. ${ }^{14}$ First, Relativists maintain that the gods are lacking knowledge of relativistic contents. Such knowledge is not available in an objective, context-independent manner. Only the god on the highest mountain can know the relativist content I am the god on the highest mountain, since only relative to his point of evaluation is this content true. Second, Guises Absolutists hold that belief and knowledge involve contents and guises. One may come to know the same absolute content under an objective, third-personal guise or under a first-personal guise. The gods' objective omniscience consists in their knowledge of all contents under objective guises. Their de se ignorance consists in their failure to know some contents under a first-personal guise. Pluralists can give a similar response, using the first element of content to do the job of guises. Russellian Absolutists deny that it is possible for the gods to know all absolute contents. Most singular contents are out of the reach even of divine beings. The gods's objective omniscience corresponds to omniscience concerning the qualitative character of their world. Their de se ignorance is haecceitistic ignorance regarding which of two qualitatively identical worlds they inhabit. ${ }^{15}$ Parallel responses regarding the other two arguments are available to each account.

\subsection{De Se Attitudes and Frege's Puzzle}

The main opposition against assigning de se attitudes a special theoretical status is based on the idea that the de se puzzle is simply an indexical variant of Frege's puzzle (Boer and Lycan, 1980; Stalnaker, 1981; Spencer, 2007; Devitt, 2013; Cappelen and Dever, 2013; Magidor,

\footnotetext{
${ }^{13}$ Compare the scrutability argument in (Torre and Weber, forthcoming).

${ }^{14}$ For instance, Lewis takes the two gods case to be compatible with both Relativism and Guises Absolutism; he opts for Relativism because of its greater simplicity (Lewis, 1979, pp. 537-538).

15 Lewis (1979, pp. 522-524) has argued that haecceitistic information would not allow the gods to resolves their ignorance. However, given the assumptions of Indexical Russellianism, in particular the gods' a priori acquaintance with their haecceity, such information would indeed enable them to know their location.
} 
2015). We can, so the idea goes, simply subsume the puzzle under the more general Frege puzzle and solve both with the same resources.

Frege's original puzzle is about language (Frege 1892). But underneath the linguistic puzzle there is a puzzle about the mind. Instances of the puzzle involve rational subjects who ascribe a certain property to an object presented in one way, but fail to ascribe the same property to that object when it appears in a different way. For instance, Ani may rationally have the belief Hesperus is a planet and fail to have the belief Phosphorus is a planet. Her rationality is explained by the fact that she is unaware of the fact that Hesperus = Phosphorus. Such ignorance of identities is the defining mark of Frege puzzle cases. Famous instances of the de se puzzle, such as Lewis's two gods or Perry's messy shopper, appear to have the same structure, appear to involve ignorance of identities, and therefore support the analogy: the god on the highest mountain does not know $I=$ the god on the highest mountain, Perry's messy shopper fails to realize $I=$ the messy shopper.

Frege's puzzle shows that reference to objects is often mediated by what Frege called "sense"-we often refer to objects via their properties. Thus understood, it seems possible to solve the puzzle within the traditional framework by replacing singular contents with contents involving the relevant properties. For instance, we no longer conceive of the belief that Hesperus is a planet as having a singular content involving Hesperus. Rather, we ascribe it a qualitative content involving the property of being the brightest celestial object in the evening sky.

The fact that Frege's puzzle is prima facie compatible with the Traditional Theory, whereas the de se puzzle is not, indicates that the two puzzles are distinct. But things are not that simple. What complicates the situation is that many senses include an indexical element (e.g. Lewis, 1997). In a sense, it is therefore correct to say that both puzzles can be solved with the same resources. However, the reason is not that de se attitudes fail to pose a unique theoretical challenge. Rather, the reason is that the de se thoroughly permeates Frege's puzzle as well; whatever is needed for an adequate treatment of de se attitudes is also required for a solution of Frege's puzzle. In the remainder of this section, we will survey additional reasons for thinking that the de se puzzle cannot simply be subsumed under Frege's puzzle. ${ }^{16}$

Resolution An important difference between de se puzzle cases and Frege puzzle cases concerns the manner in which such cases can be resolved. Assuming that senses are nonindexical, Frege puzzle cases can be resolved using objective information alone, but de se puzzle cases cannot be so resolved. To resolve a puzzle case is to remove the subject's underlying ignorance of identities. According to the above analysis, Ani's ignorance that Hesperus $=$ Phosphorus consists in her failing to realize that one and the same object is both the brightest celestial object in the evening sky and the brightest celestial object in the morning sky. When she learns that both properties are co-instantiated, her ignorance is removed. The relevant information is objective, and only concerns the instantiation of

${ }^{16}$ See (Torre and Weber, forthcoming) for further details. 
properties. Assuming that the arguments in $\$ 3.1$ are essentially correct, indexical ignorance cannot be resolved with purely objective information.

Shareability Another important difference between de se puzzle cases and Frege puzzle cases is that Frege puzzle cases are shareable in a way in which de se puzzle cases are not. Consider the case in which Ani believes that Hesperus is a planet and believes that Phosphorus is not a planet. This case involving a Frege puzzle is shareable in the following way: Another individual, Aren, could also believe the same contents as Ani, and thereby find himself in the same Frege Puzzle case. Furthermore, just like Ani, Aren gains new information when he learns that Hesperus is Phosphorus. Ani and Aren can be just alike with respect to their content before realizing Hesperus is Phosphorus, as well as just alike after realizing that Hesperus is Phosphorus: both gain new information when they learn that Hesperus is Phosphorus and this change in information is reflected in a change in content.

However, de se puzzle cases are not shareable in the same way. Consider the case in which Perry, prior to realizing that he himself is making a mess, believes of the messy shopper that he is making a mess. Call whatever content Perry believes prior to his realization ' $\mathrm{C} 1$ '. A fellow shopper Susan can presumably have a belief with the same content ' $\mathrm{C} 1$ ' and thereby believe of Perry that he is making a mess. However, when Perry realizes that he himself is making a mess, he gains new information and presumably comes to believe a new content ' $C 2$ '. However, it does not seem that Susan can share this change in belief content: there does not seem to be any plausible candidate for $\mathrm{C} 2$ such that $\mathrm{C} 2$ is the same content that Perry believes after his realization, and it involves a change in belief for Susan. ${ }^{17}$

Non-Fregean de se puzzle cases Resolution and Shareability suggest that even if all de se puzzle cases were structurally similar to Frege puzzle cases, their treatment would still require additional theoretical resources. But there is a further problem: some de se puzzle cases do not have a Fregean structure. Frege puzzle cases involve ignorance of identities, but not all de se puzzle cases exhibit such ignorance. The most prominent example of a non-Fregean de se puzzle case is Perry's (1977) bear-attack case (see §4); for other examples see (Perry, 2006; Weber, 2015, 2016; Stalnaker, 2016; Torre and Weber, forthcoming). A skeptic may suspect that we have perhaps overlooked a hidden piece of identity-ignorance. The modified two gods case in $\S 3.1$ proves that this is not so: it is a de se puzzle case, but there can be no ignorance of identities involved, since the two gods are indexically and non-indexically omniscient.

\section{De Se Attitudes and Action Explanation}

Much of the literature on de se attitudes focuses either explicitly or implicitly on the role of such attitudes in action explanation. Many of the well-known examples involve an action that

\footnotetext{
${ }^{17}$ For a discussion of various candidate contents for C2 and why they are implausible, see (Torre and Weber, forthcoming, section 3).
} 
seems to require de se attitudes in order to explain why the action occurred. Consider perhaps the best-known such example, Perry's Messy Shopper:

I believed at the outset that the shopper with a torn sack was making a mess. And I was right. But I didn't believe that I was making a mess. That seems to be something I came to believe. And when I came to believe that, I stopped following the trail around the counter, and rearranged the torn sack in my cart. My change in beliefs seems to explain my change in behavior (Perry, 1979, p. 5, our emphasis).

Perry's claim is that an indexical belief is necessary in order to explain why Perry changed his behavior: why he finally bent down to adjust the leaking bag of sugar in his shopping cart.

Some have questioned the extent that examples like the Messy Shopper establish that de se attitudes are required for action explanation (e.g. Spencer, 2007, Cappelen and Dever, 2013, Chapter 3, Magidor, 2015). In recent years, however, substantial work has been done to more fully articulate such arguments. ${ }^{18}$ Before considering such arguments, it is worth spending some time clarifying exactly what thesis about the connection between de se attitudes and action explanation they aim to establish. Frequently in the literature on de se attitudes and action explanation, the thesis under dispute seems to be the following.

(AE1) All successful action explanations necessarily require an appeal to de se attitudes. ${ }^{19}$

However such a thesis is far too strong and no one who maintains that de se attitudes play a special role in action explanation should accept it. It is not difficult to come up with merely possible models of action that do not require an appeal to indexical attitudes in explaining action. Cappelen and Dever (ms) provide several, one of which is an occasionalist world in which all events are brought about by an occasionalist god: "When God sees that Jones wants a beer, and that Jones believes there are beers in the refrigerator, God causes Jones to go to the refrigerator" (Cappelen and Dever, ms, p.3). Maintaining that de se attitudes play a distinctive role in action explanation does not require maintaining that de se attitudes are necessary in the explanation of all possible actions including in those distant possibilities in which actions might be produced by different mechanisms.

So what distinctive role do de se attitudes play in action explanation? The most developed arguments for the need for de se attitudes in action explanation all involve cases of a certain sort. In one such case, Al is being chased by a bear and Betty is not (Perry, 1977; Ninan, chapter $x \mathrm{x}$, this volume). Al curls up into a ball to avoid being mauled, and Betty waves

\footnotetext{
18 There are a number of discussions in the literature aimed at arguing for the necessity of indexical attitudes in action explanation, e.g. Lima (2018); Ninan (2016; chapter XX, this volume); Torre (2018); Valente (2017).

19 Cappelen and Dever take the thesis at issue to be "Impersonal action rationalizations (IAR) are necessarily incomplete because of a missing indexical component." Cappelen and Dever $(2013$, p.30) provide a number of quotes that are plausibly interpreted as endorsing (AE1).
} 
her arms to frighten away the bear. In another case, David's pants are on fire, and Susan's are not (Torre, 2018). David stops, drops and rolls, and Susan runs to get the fire extinguisher. Cases such as these involve two agents who are in distinct predicaments (chased by a bear/not chased by a bear; pants on fire/pants not on fire). Furthermore, the agents are fully aware of their own predicament and the other agent's predicament; there is no identity confusion or confusion with respect to whose pants are on fire or who is being chased by a bear. Another feature of such cases is that awareness of being in distinct predicaments motivates the agents to perform actions of distinct action-types: Al is motivated to curl up in a ball, whereas Betty is motivated to wave her arms; David is motivated to stop, drop and roll, whereas Susan is motivated to get the fire extinguisher. Let us call such cases Known Distinct Predicament (KDP) cases. KDP cases are cases in which there are agents in distinct predicaments in the sense that one has a particular feature that the other lacks, the agents are aware of their own predicament and that of the other agent, and this awareness of being in distinct predicaments motivates the agents to perform actions of distinct action-types. We maintain that considering KDP cases provides support for the following claim:

(AE2) Our best theory of action explanation requires an appeal to de se attitudes.

Note that (AE2) is weaker than (AE1). (AE2) is compatible with the existence of actions that can be explained without appeal to de se attitudes. Nonetheless, (AE2) maintains that de se attitudes are required in our best theory of action explanation. KDP cases provide compelling arguments for (AE2) and establishing this principle vindicates the claim that de se attitudes play a significant role in action explanation.

The argument for (AE2) involves recognizing that the Traditional Theory of Attitudes presented in $\$ 2$, when combined with a plausible thesis connecting mental attitudes and action explanation, provides the wrong predictions in KDP cases. In order to provide the correct prediction in such cases, it is argued further that the Traditional Theory of Attitudes must be amended in such a way as to introduce de se attitudes.

It is natural to appeal to an agent's beliefs and desires in explaining why she performed a particular action. Why did Ani get milk from the fridge? Because she desired milk, believed that there was milk in the fridge, believed that if she opens the fridge, she will be able to grab the milk, etc. Furthermore, if appealing to these beliefs and desires successfully explains why Ani performs this action, anyone with the same relevant beliefs and desires as her will act similarly, other things being equal. If Aren has the same relevant beliefs and desires as Ani, other things being equal, Aren will also get milk from the fridge. Of course, the plausibility of this claim depends very much on the 'other things being equal' clause. If Aren is paralysed, has a fear of fridges, or suffering from vivid hallucinations, then sharing Ani's relevant beliefs and desires will not necessarily result in Aren performing the same action. ${ }^{20}$ These plausible

\footnotetext{
${ }^{20}$ As Ninan (2016, p.102) notes, it is "notoriously difficult to explain what it is for 'other things to be equal"'; however Ninan offers a partial list of conditions under which other things are not equal.
} 
claims about the connection between shared attitudes and action explanation can be stated in the following thesis:

Explanation: If the explanation for why $S$ performed an action of action-type $\alpha$ is the fact that $S$ has attitudes $a_{1}, \ldots a_{n}$, then if $T$ shares the attitudes $a_{1}, \ldots a_{n}$ then, other things being equal, $T$ will also perform an action of action-type $\alpha$.

Let us refer to the Traditional Theory of Attitudes introduced in §2together with Explanation as the Traditional Theory of Attitudes + Explanation or TTA+E. What is it for two subjects to share attitudes according to TTA+E? Given the Traditional Theory's commitment to Binary Relationism and Shareability, two subjects share an attitude just in case they stand in the same attitudinal relation to one and the same content. For example, Ani and Aren share the belief that there is milk in the fridge just in case they both stand in the belief relation to the content that there is milk in the fridge.

The argument for the claim that TTA+E provides the wrong prediction in KDP cases can be summarized as follows:21 $\mathrm{Al}$ and Betty are out for a walk in the woods and a bear begins to chase $\mathrm{Al}$ (and let us suppose that the bear is not chasing Betty). Al believes that he is being chased by a bear, he desires not to be mauled, and he believes that if he curls up in a ball, he will not be mauled. Al curls up in a ball and avoids being mauled. Suppose that Betty shares Al's attitudes. Given Absolutism, if Betty believes what Al believes when Al believes that he is being chased by a bear, Betty believes that $\mathrm{Al}$ is being chased by a bear. ${ }^{22}$ Sharing $\mathrm{Al}^{\prime}$ 's belief cannot involve believing that Betty is being chased by a bear since this belief is false and, by Absolutism, Al's belief is true for every subject that shares it. Similarly, in sharing his attitudes, Betty desires that Al not be mauled and he believes that if Al curls up, he will avoid being mauled. If Betty shares all Al's relevant attitudes, then, by Explanation, Betty will also curl up. However, this is the wrong result: given his attitudes, Betty would presumably perform an action of a different action-type such as trying to frighten away or distract the bear, using his bear mace, calling for help, etc. So, TTA+E predicts that Betty would perform an action of the same action-type as Al: curl up in a ball. But this is the wrong result and so the TTA+E must be false.

We do not yet have an argument for the conclusion that de se attitudes are required in explaining Al's action. Rather we have an argument for the conclusion that one of the theses of TTA+E must be rejected. In $\$ 2$ we outlined how rejecting one of the theses of the Traditional Theory involves adopting an account of indexical attitudes (either Relativism, Guises Absolutism, Russellian Absolutism, or Pluralism). The Relativist response to the above argument would be that the content of Al's belief that he would express by saying 'I am being chased by a bear' is an interesting content true at all and only those individuals that are being chased by a bear. So, for Betty to share this content would be for Betty to falsely believe that she herself is being chased by a bear. Explanation could then be upheld since it is plausible to claim that given such shared attitudes, Betty would also curl up in a ball.

\footnotetext{
${ }^{21}$ A more thorough and nuanced version of the argument can be found in (Ninan, this volume, chapter XX).

22 Or at least a proposition that is truth-conditionally equivalent to the proposition that $\mathrm{Al}$ is being chased by a bear.
} 
If the Guises Absolutist reserves the term 'content' for traditional contents that are absolute and shareable, she will deny that sameness of content entails sameness of action. $\mathrm{Al}$ and Betty may share the same traditional contents (both believe that $A l$ is being chased by a bear, both desire that $A$ ( not be mauled), but they do not perform actions of the same actiontype because they believe and desire these contents under different guises. Likely, the Guises Absolutist will accept a version of Explanation that appeals to guises instead of traditional contents: if two agents share the relevant guises, then they will perform actions of the same action-type. In this sense, the version of Explanation that the Guises Absolutist adopts will be similar to that adopted by the relativist except that it will be formulated in terms of shared guises rather than shared contents.

The Russellian Absolutist response to the above argument would be to reject Shareability and maintain that Betty cannot believe what Al believes when he (Al) believes that he is being chased by a bear. In believing that he himself is being chased by a bear, there is some absolute, singular proposition that Al believes that is unshareable: no one distinct from Al can believe it. Although this response manages to uphold Explanation, it does so by claiming that in cases like the bear chase, it is vacuously true since the explanation of $\mathrm{Al}^{\prime} \mathrm{s}$ action involves unshareable contents. So although Explanation is upheld, this response renders it idle in cases involving de se attitudes. If we are inclined to think that Explanation provides an informative thesis about the connection between mental attitudes and action, this seems to provide reason to favour Relativism or Guises Absolutism over accounts like Russellian Absolutism that reject Shareability.

So what is special about de se attitudes when it comes to action explanation? It is not plausible to maintain that all successful action explanations necessarily require an appeal to de se attitudes. The proponent of de se attitudes should grant that there are some actions that can be successfully explained without appeal to de se attitudes, especially in merely possible cases in which actions might be produced by different causal mechanisms. Nonetheless, granting this doesn't mean denying that de se attitudes play a significant role in action explanation. As KDP cases demonstrate, our best theory for explaining actions seems to require an appeal to de se attitudes.

\section{Are De Se Beliefs Epistemically Special?}

Many maintain that de se beliefs have distinctive epistemic properties. Most commonly it is claimed that they are immune from a certain kind of error, specifically that they are immune from error through misidentification. Suppose Bryan sees a woman in the distance walking a terrier and he judges "Aunt Lillian is walking a terrier". There are two ways in which Bryan's judgment might be mistaken. It might be mistaken in virtue of ascribing a property to Aunt Lillian that she doesn't in fact have; for example, she may be walking a retriever. Or Bryan might be mistaken, not in the property he ascribes, but in who or what he is ascribing it to: it might not be Aunt Lillian, but Aunt Lillian's neighbor who is walking a terrier. The latter type of mistake has been called an error through misidentification. 
Many have noted that first-person judgments seem to be immune to this sort of mistake. When Bryan judges that he himself has his legs crossed, he might be mistaken about the position of his legs, but it seems impossible for him to be mistaken regarding whom he is ascribing the property to. This purported immunity to error through misidentification (henceforth 'IEM') seems to grant a special status to first-person or de se judgments: they seem to be immune from error in a way in which judgments about others are not.

It is not a straight-forward matter to articulate exactly what IEM is. If Bryan acquires the judgment that his legs are crossed through the usual means, by proprioception, it seems plausible that the judgment is immune from error through misidentification ${ }^{23}$ : there is a possibility that the belief is false, for example if his proprioceptive system is malfunctioning, but it is difficult to see how it could be false because he mistakes himself for a distinct individual that has crossed legs. If, on the other hand, Bryan forms the belief by looking into a mirror during yoga class while anesthetized from the waist down, it does seem possible that his judgment could be false by mistaking himself for a different individual that has crossed legs, "I thought it was me whose legs were crossed, but it's that guy!". This suggests that whether a judgment exhibits IEM depends on the way in which the judgment is acquired.

An attempt at characterizing IEM can be given as follows:

(IEM) $S$ 's judgment that ' $a$ is $F$ ' arrived at through way $w$ is immune to error through misidentification just in case there are no possibilities in which $S$ acquires the judgement that ' $a$ is $F$ ' through way $w$, the judgment is false, and it is false in virtue of mistaking $a$ for something that is truly $F^{24}$

In investigating whether de se judgments are epistemically special in virtue of exhibiting IEM, we will focus on the following two questions:

(1) Do some de se judgments exhibit IEM?

(2) Assuming that some de se judgments exhibit IEM, is this indicative of a special feature of de se judgments?

One who wishes to maintain that exhibiting IEM is a special epistemic feature of de se judgments will maintain, not only that de se judgments exhibit IEM, but that this highlights something distinctive about such judgments. One who denies that IEM accounts for a special epistemic feature of de se judgments could either maintain that they do not in fact exhibit IEM (deny (1)) or that they do, but this isn't indicative of anything special about de se

\footnotetext{
${ }^{23}$ Although we consider a challenge to this claim below.

${ }^{24}$ Of course how 'ways' are understood in this characterization of IEM will be important. There is disagreement over this and our use of this term is meant to remain neutral with respect to different conditions under which a judgment exhibits IEM (See Coliva,2006; Wright, 2012; Recanati, 2012a).
} 
judgments; rather it's a feature that holds of a broader class of singular judgments (accept (1), but deny (2)). We address both questions (1) and (2) below.

\subsection{Do Some De Se Judgments Exhibit IEM?}

Most in the literature agree that there are some cases of de se judgments that are immune to error through misidentification. A classic example of a de se judgement that exhibits IEM is

(P) I feel pain.

Sydney Shoemaker writes:

The statement "I feel pain" is not subject to error through misidentification: it cannot happen that I am mistaken in saying "I feel pain" because, although I do know of someone that feels pain, I am mistaken in thinking that person to be myself. (1968, p. 557)

Cappelen and Dever (2013) are among the few who deny that any de se judgments exhibit IEM. In fact, they deny that any judgments whatsoever exhibit IEM. In arguing against the claim that de se judgments exhibit IEM, they consider a case in which Bryan is wired up in such a way that he sometimes receives proprioceptive information about John's legs. Being aware of this, it makes sense for Bryan to wonder whether it is John's legs that are crossed rather than his own. "So even if [Bryan] has not been deviantly wired, he is not immune to error, because until the possibility of deviant wiring has been eliminated, the possibility of error due to misidentification cannot be eliminated" (Cappelen \& Dever, 2013, p.131). They further claim that this counterexample provides a "general recipe" for showing that de se judgments in general fail to exhibit IEM "for any of [Bryan's] beliefs about himself and any source of evidence for that belief, we can imagine him being such that he sometimes receives evidence of that sort from someone else's state" (Cappelen \& Dever, 2013, p.131).

Whether or not one thinks that this deviant wiring case succeeds in showing that Bryan's judgment fails to exhibit IEM, it isn't clear that the general recipe they propose succeeds in demonstrating the strong claim that they are arguing for: that no de se judgments, including judgments like (P), exhibit IEM. ${ }^{25}$ Being deviantly wired up to John in such a way

\footnotetext{
${ }^{25}$ In response to such deviant wiring cases, many in the literature follow Shoemaker in distinguishing between de facto IEM and logical IEM. IEM is de facto if it is due to contingent features of the circumstances. One could respond to such deviant wiring cases by claiming that judgments arrived at through proprioception are de facto IEM rather than logical IEM. Unless more is said to spell out what de facto IEM amounts to, the distinction runs the risk of undermining the epistemic authority of IEM.'Immunity' is obviously a modal claim: that one will not arrive at a certain kind of error in a range of possibilities. The objector to IEM denies this by pointing to a possibility in which the subject will arrive at an error of misidentification. What principled restriction on possibilities rules out such deviate wiring cases as relevant for assessing IEM yet upholds IEM as an epistemically significant property of judgments? See McGlynn (2016) for one attempt at providing a principled distinction between logical and non-logical IEM in terms of safety from error.
} 
that Bryan feels pain when John steps on a tack would presumably not make Bryan's judgment 'I feel pain' false. It is difficult to see how we would construct the deviant wiring case in order to introduce the possibility of error through misidentification in Bryan's judgment 'I feel pain' and similarly for other de se judgments involving phenomenal experiences like 'I am experiencing redness' or 'I feel as though my legs are crossed'. So even if one grants Cappelen and Dever's argument for the claim that judgments of 'My legs are crossed' gained through proprioception fail to exhibit IEM, they haven't provided a sufficiently general argument for the claim that no de se judgments, including relatively uncontroversial ones like 'I feel pain', exhibit IEM.

\subsection{Assuming That Some De Se Judgments Exhibit IEM, Is This Indicative of a Special Feature of De Se Judgments?}

Let us assume that there are genuine cases of de se judgments that exhibit IEM. It seems implausible to maintain that exhibiting IEM is a distinctive feature of de se judgments in the sense that all and only de se judgments exhibit IEM. There are relatively uncontroversial cases both of de se judgments that fail to exhibit IEM and of non-de se judgments that exhibit IEM. For example, Bryan could form the de se judgment that he himself has Groat's disease from reading through his medical records. Given the way he acquired the de se judgment, it is not immune from error through misidentification because there is a possibility in which his belief is false in virtue of mistaking himself for another patient that truly has Groat's disease (for example, if he reads another patient's records believing that they are his own). Many claim that demonstrative judgments like that is a lemon, based on vision, exhibit IEM: it seems possible that the demonstrated object lacks the property ascribed, but it does not seem possible for the subject to misidentify the demonstrated object with another that truly has the property.

However, the fact that IEM is not unique to de se judgments does not mean that exhibiting IEM is not indicative of a special epistemic feature of de se judgments. It may well be that the IEM exhibited by many de se judgments nonetheless results from certain distinctive features of de se attitudes. The IEM exhibited by demonstrative judgments may be derivative from, or of a different sort from, that exhibited by de se judgments. One such account is given by Francois Recanati (2012a). ${ }^{26}$ Recanati maintains that de se judgments exhibit IEM when they are directly based on experience. There is a mode associated with certain experiences that makes them about the subject who has them. When Bryan forms the judgment 'I have crossed legs' based on proprioception, the proprioceptive mode ensures that the content is about the subject, and the content of his judgment is a property: the property of having crossed legs. The content of the judgment contains no identification of the subject and so no misidentification is possible: the IEM exhibited by the judgment results from

\footnotetext{
26 Others who claim that the exhibiting of IEM by de se judgments derives from distinctive features of the account of de se attitudes include Higgenbotham (2003) and García-Carpintero (2018), both of whom claim that IEM of de se judgments results from their token-reflexive nature.
} 
the fact that the subject-less content having crossed legs of the judgment is associated with an experiential mode that must concern the subject of the experience.

Other theorists, for example, Daniel Morgan (2012), Jason Stanley (2011), and Crispin Wright (2012), follow Gareth Evans (1982) in providing a more general account of when singular judgments exhibit IEM that denies that this epistemic feature highlights anything distinctive about de se judgments. They endorse what has come to be called the Simple Explanation': that judgments exhibit IEM just in case they are not based on an identity statement. ${ }^{2728}$ The Simple Explanation has the implication that any singular judgment that is not based on an identity will be IEM. Wright writes, "According to [the Simple Explanation], IEM is a phenomenon of singular judgment in which no significant identification, associating one singular mode of presentation with another, features as part of the grounds. It is thus, in particular, a feature of basic singular thought. Moreover, a proponent of the Simple [Explanation] may continue, there is absolutely nothing here that is peculiar to the first person. IEM I-thoughts are simply one kind of basic singular thought - basic singular thoughts which concern oneself" (Wright 2012, 255). So embracing the Simple Explanation seems to involve granting that exhibiting IEM is not indicative of a special feature of de se judgements, but rather stems from a more general fact about the basis of singular judgments.

However it is far from clear that embracing the Simple Explanation requires one to accept that the IEM exhibited by de se judgments fails to be indicative of a special feature of such judgments. It may well be that there is a distinctive mechanism that produces de se judgments and the mechanism ensures that such judgments are not based on identity statements. This is consistent with the claim that there are other non-de se judgments that exhibit IEM produced in a different way. Recanati's account provides one such case in point: the nature of the experiential mode and the content associated with certain de se attitudes precludes an identification component as part of the subject's grounds for the judgment, and so the Simple Explanation seems to support, rather than undermine, such an account.

The disagreement in the literature about what sorts of judgments exhibit IEM, as well as the necessary background conditions required for a judgment to exhibit IEM, suggest that IEM is not a unitary epistemic property possessed by some judgments and lacked by others. Rather there are different kinds of IEM perhaps resulting from differences in the way in which the judgment was acquired. Nonetheless, some de se judgments, such as those involving the

\footnotetext{
27 Our used of 'based on' is purposefully vague. There is disagreement about what it is for a singular judgment to be based on an identity statement: some claim that it ought to be part of the subject's grounds whereas others claim it is sufficient for an identity statement to be presupposed by the judgment. Coliva (2006) claims that this distinction motivates the classification of two different varieties of IEM.

${ }^{28}$ A challenge to the Simple Explanation is another type of error through of misidentification pointed out by James Pryor (1999): Which-misidentification. Errors of Which-misidentification don't seem to be based on identity statements, but rather based on existential statements ("There is a skunk in my backyard") that are falsely witnessed ("That animal is a skunk"). However the challenge to the Simple Explanation raised by the phenomenon of Which-misidentification seems to be merely classificatory: either one can deny that errors of Which-misidentification are the same sort of phenomenon as errors of classic de re-misidentification and insist that the Simple Explanation explains the latter only. Or one could grant that Pryor has highlighted a different way in which the same phenomenon can arise and expand the Simple Explanation to claim that judgments exhibit IEM just in case they fail to be based on an identity statement or existential statements.
} 
self-ascription of phenomenal states like $(P)$, seem to exhibit the strongest form of IEM: logical IEM, and so the question of whether this is indicative of a special epistemic feature of such judgments deserves further investigation.

\section{Conclusion}

In this chapter we have attempted to highlight the distinctive role that de se attitudes play in cognition and action. We have also considered the question of whether de se judgments possess a distinctive epistemic property, namely immunity to error through misidentification. We take the case against the Traditional Theory of Attitudes to be a strong one: the role that contents play in cognition and action explanation requires us to adopt contents that are either non-absolute or unshareable. We have sketched different ways in which the Traditional Theory can be modified so as to accommodate de se attitudes. We conclude that there are compelling reasons for giving de se attitudes a prominent place in our best theory of mind.

\section{Further reading}

Cappelen, H. and J. Dever (2013). The Inessential Indexical: On the Philosophical Insignifance of Perspective and the First Person. Oxford: Oxford University Press.

Feit, N. (2008). Belief about the Self: A Defense of the Property Theory of Content. Oxford: Oxford University Press.

Lewis, D. (1979). Attitudes de dicto and de se. The Philosophical Review 88, 513-43.

McGlynn, A. (2016). Immunity to Error Through Misidentification and the Epistemology of De se Thought. In M. García-Carpintero and S. Torre (eds.), About Oneself: De se Thought and Communication, pp. 25-55. Oxford: Oxford University Press.

Ninan, D. (2016). What is the problem of de se attitudes? In M. García-Carpintero and S. Torre (Eds.), About Oneself: De Se Attitudes and Communication, pp. 86-120. Oxford University Press.

Perry, J. (1979). The problem of the essential indexical. Noûs 13, 26-49.

Schwarz, W. (2017). Diachronic norms for self-locating beliefs. Ergo 4, 709-738

Torre, S. and C. Weber (under review). De se puzzles and Frege puzzles.

\section{References}

Austin, D. F. (1990). What's the Meaning of 'This'? Ithaca: Cornell University Press. 
Boër, S. and W. Lycan (1980). Who, me? The Philosophical Review 89, 427-466.

Braun, D. (2002). Cognitive significance, attitude ascriptions, and ways of believing propositions. Philosophical Studies 1-2(108), 65-81.

Cappelen, H. and J. Dever (2013). The Inessential Indexical: On the Philosophical Insignifance of Perspective and the First Person. Oxford: Oxford University Press.

Chalmers, D. (2002). The components of content. In D. Chalmers (Ed.), Philosophy of Mind: Classical and Contemporary Readings, pp. 608-633. Oxford University Press.

Chalmers, D. (2011). Frege's puzzle and the objects of credence. Mind 120(4), 587-635.

Devitt, M. (2013). The myth of the problematic de se. In A. Capone and N. Feit (Eds.), Attitudes De Se: Linguistics, Epistemology, Metaphysics. CSLI Publications.

Coliva, A. 2006. Error through misidentification: some varieties. Journal of Philosophy 103: 403-425.

Egan, A. (2007). Epistemic modals, relativism and assertion. Philosophical Studies 133, 1-22.

Evans, G. (1982). Varieties of Reference. Oxford University Press.

Frege, G. (1892). Uber Sinn und Bedeutung. Zeitschrift für Philosophie und philosophische Kritik 100, 25-50.

García-Carpintero, M. (2018). "De se Thoughts and Immunity to Error through Misidentification" Synthese 195 (8): 3311-3333.

Gibbard, A. (2012). Meaning and Normativity. Oxford: Oxford University Press.

Jackson, F. (1982). Epiphenomenal qualia. Philosophical Quarterly XXXII(127), 127-136.

Kaplan, D. (1989). Demonstratives. In J. Almog, J. Perry, and H. Wettstein (Eds.), Themes from Kaplan, pp. 481-614. New York: Oxford University Press.

Kwon, H. (2010). Self-Identification and Self-Knowledge. Phd thesis, MIT.

Kwon, H. (2017). Mary and the two gods: Trying out an ability hypothesis. The Philosophical Review 126(2), 191-217.

Lewis, D. (1979). Attitudes de dicto and de se. The Philosophical Review 88, 513-43.

Lewis, D. (1997). Naming the colours. Australasian Journal of Philosophy 75, 325-342. 
Magidor, O. (2015). The myth of the de se. Philosophical Perspective 29, 249-283.

McGlynn, A. (2016). Immunity to Error Through Misidentification and the Epistemology of De se Thought. In M. García-Carpintero and S. Torre (eds.), About Oneself: De se Thought and Communication, pp. 25-55. Oxford: Oxford University Press.

Meacham, C. (2010). Unravelling the tangled web: Continuity, internalism, non-uniqueness and self-locating beliefs. In T. Szabó-Gendler and J. Hawthorne (Eds.), Oxford Studies in Epistemology, Volume 3, pp. 86-125. Oxford: Oxford University Press.

Morgan, D. (2012). Immunity to error through misidentification: What does it tell us about the de se. In S. Prosser \& F. Recanati (Eds.), Immunity to Error through Misidentification: New Essays (pp. 104-123). Cambridge: Cambridge University Press.

Ninan, D. (2016). What is the problem of de se attitudes? In M. García-Carpintero and S. Torre (Eds.), About Oneself: De Se Attitudes and Communication, pp. 86-120. Oxford: Oxford University Press.

Perry, J. (1977). Frege on demonstratives. The Philosophical Review 86(4), 474-97.

Perry, J. (1979). The problem of the essential indexical. Noûs 13, 26-49.

Perry, J. (2001). Reference and Reflexivity. Stanford: CSLI Publications.

Perry, J. (2006). Stalnaker on indexical belief. In J. J. Thomson and A. Byrne (Eds.), Content and Modality: Themes from the Philosophy of Robert Stalnaker, pp. 204-221. New York: Oxford University Press.

Pryor, J. 1999. Immunity to error through misidentification. Philosophical Topics 26: 271-304.

Recanati, F. (2012a). Immunity to error through misidentification: What it is and where it comes from. In S. Prosser \& F. Recanati (Eds.), Immunity to Error through Misidentification: New Essays,pp. 180-201. Cambridge: Cambridge University Press.

Recanati, F. (2012b). Mental Files. Oxford: Oxford University Press.

Recanati, F. (2016). Mental Files in Flux. Oxford: Oxford University Press.

Russell, B. (1912). The Problems of Philosophy. London: Williams and Norgate. 9th impression, with appendix, published Oxford: Oxford University Press 1980

Salmon, N. (1986). Frege's Puzzle. Cambridge, MA: MIT Press. 
Schwarz, W. (2012). Changing minds in a changing world. Philosophical Studies 159(2), 219239.

Shoemaker, S. (1968). Self-knowledge and self-awareness. Journal of Philosophy, 65, 555567.

Soames, S. (1987). Direct reference, propositional attitudes, and semantic content. Philosophical Topics 15, 47-87.

Spencer, C. (2007). Is there a problem of the essential indexical? In M. O'Rourke and C. Washington (Eds.), Situating Semantics: Essays on the Philosophy of John Perry. Cambridge: MIT Press.

Stalnaker, R. C. (1981). Indexical belief. Synthese 49, 129-151.

Stalnaker, R.C. (1999). Context and Content: Essays on Intentionality in Speech and Thought. Oxford: Oxford University Press.

Stalnaker, R. C. (2008). Our Knowledge of the Internal World. New York: Oxford University Press.

Stalnaker, R. C. (2016). Modelling a perspective on the world. In M. García-Carpintero and S. Torre (Eds.), About Oneself: De Se Content and Communication, pp. 121-139, Oxford: Oxford University Press.

Stanley, J. (2011). Know How. Oxford: Oxford University Press.

Titelbaum, M. G. (2016). Self-locating credences. In The Oxford Handbook of Probability and Philosophy, Chapter 31, pp. 666-680. Oxford University Press.

Torre, S. (2017). In defense of de se content. Philosophy and Phenomenological Research XCVII(1), 172-189.

Torre, S. and C. Weber (forthcoming). De se puzzles and Frege puzzles. Inquiry.

Weber, C. (2013). Centered communication. Philosophical Studies 166(S), 205-223.

Weber, C. (2015). Against Stalnaker on self-location. Philosophical and Phenomenological Research XC(3), 640-663.

Weber, C. (2016). Being at the centre: Self-locating in thought and langauge. In M. GarcíaCarpintero and S. Torre (Eds.), About Onself: De Se Thought and Communication. Oxford University Press. 
Wright, C. (2012). Reflections on François Recanati's 'immunity to error through misidentification: What it is and where it comes from'. In S. Prosser \& F. Recanati (Eds.), Immunity to error through misidentification: New essays, pp. 247-280. Cambridge: Cambridge University Press.

Zimmermann, T. E. (1991). Kontextabhängigkeit. In A. von Stechow and D. Wunderlich (Eds.), Semantik/Semantics: Ein internationales Handbuch der zeitgenössischen Forschung, pp. 156229. Berlin/New York: Walter de Gruyter. 